\title{
The increasing importance of histologic grading in tailoring adjuvant systemic therapy in 30,843 breast cancer patients
}

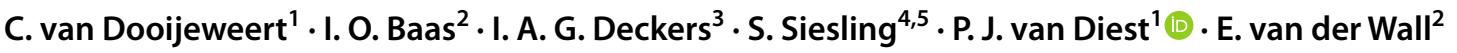

Received: 19 August 2020 / Accepted: 6 January 2021 / Published online: 30 January 2021

(c) The Author(s) 2021

\begin{abstract}
Purpose The large variation in histologic grading of invasive breast cancer (IBC) that has been reported likely influences tailoring adjuvant therapy. The role of grading in therapeutic decision-making in daily practice, was evaluated using the Dutch national guidelines for IBC-management.

Methods Synoptic reports of IBC resection-specimens, obtained between 2013 and 2016, were extracted from the nationwide Dutch Pathology Registry, and linked to treatment-data from the Netherlands Cancer Registry. The relevance of grading for adjuvant chemotherapy $(\mathrm{aCT})$ was quantified by identifying patients for whom grade was the determinative factor. In addition, the relation between grade and aCT-administration was evaluated by multivariate logistic regression for patients with a guideline-aCT-indication.

Results 30,843 patients were included. Applying the guideline that was valid between 2013 and 2016, grade was the determinative factor for the aCT-indication in $7744(25.1 \%)$ patients, a percentage that even increased according to the current guideline where grade would be decisive for aCT in 10,869 (35.2\%) patients. Also in current practice, the indication for adjuvant endocrine therapy (aET) would be based on grade in 9173 (29.7\%) patients. Finally, as patients with lower-grade tumors receive aCT significantly less often, grade was also decisive in tailoring aCT de-escalation.

Conclusions In the largest study published so far we illustrate the increasing importance of histologic grade in tailoring adjuvant systemic breast cancer therapy. Next to playing a key-role in aCT-indication and de-escalation, the role of grading has expanded to the indication for aET. Optimizing histologic grading by pathologists is urgently needed to diminish the risk of worse patient outcome due to non-optimal treatment.
\end{abstract}

Keywords Invasive breast cancer $\cdot$ Histologic grade $\cdot$ Guideline adherence $\cdot$ Adjuvant systemic treatment $\cdot$ Real-world data

P. J. van Diest

p.j.vandiest@umcutrecht.nl

1 Department of Pathology, University Medical Center Utrecht, PO Box 85500, 3508 GA Utrecht, The Netherlands

2 Department of Medical Oncology, University Medical Center Utrecht, Utrecht, The Netherlands

3 Foundation PALGA (the Nationwide Network and Registry of Histo- and Cytopathology in the Netherlands), Houten, The Netherlands

4 Department of Research, Netherlands Comprehensive Cancer Organization, Utrecht, The Netherlands

5 Department of Health Technology \& Services Research, Technical Medical Centre, University of Twente, Enschede, The Netherlands

\section{Introduction}

Breast cancer is the most common type of cancer in women worldwide, with an incidence of 2.1 million [1]. In the Netherlands, invasive breast cancer (IBC) accounts for approximately 15,000 new diagnoses annually $[2,3]$.

Aiming to provide individual IBC-management, treatment is guided by clinicopathologic biomarkers [4-12]. For example, the indication for adjuvant systemic chemotherapy $(\mathrm{aCT})$, is based on patient factors like age and performance status, and classic pathology features like tumor size, lymphnode status, grade, and estrogen- (ER), progesterone- (PR), and HER2-receptor status [5-9, 11, 13, 14]. Of these, histologic grade, according to the (globally used) Bloom and Richardson grading classification, is a biomarker that has consistently been found to be associated with breast cancerspecific and disease free-survival $[13,14]$. 
Within the Dutch IBC guideline, in line with global breast cancer guidelines [4-10], grade plays an important role in the selection of individual patients considered to experience benefit from aCT [11]. We have previously shown that substantial grading variation exists between Dutch pathology laboratories in daily practice [15], which makes it highly likely that tumors are under- and over-graded in specific pathology laboratories and/or by specific pathologists. In view of its decisive role in personalized treatment, this variation is worrisome to the least since it may lead to under- or over-treatment.

In selecting the right patients for adjuvant systemic chemotherapy (aCT), most guidelines roughly distinguish three groups, i.e. estrogen $(\mathrm{ER}+)$ - and or progesterone $(\mathrm{PR}+)$-driven HER2-negative IBC, HER2-driven (ER-/ PR-, HER2 +) IBC and triple negative IBC (TNBC) (ER-, PR-, HER2-) [4, 6, 7, 10-12]. For HER2-driven IBC and TNBC, these guidelines state that practically all patients should receive aCT [6, 7, 10-12]. In contrast, for ER and/ or PR-driven IBC, focus has shifted to tailored aCT deescalation, thereby mostly maintaining adjuvant endocrine therapy (aET).

More recently, gene-expression profiling (GEP) by multigene-assays (i.e. the 21-gene recurrence score assay (21-GS/Oncotype DX) and the 70-gene signature (70-GS/ MammaPrint) has been introduced as a supportive tool in clinical-decision making for ER +/HER2- IBC [5-9, 11, 13, 14]. The Dutch breast cancer guideline [11] encourages the 70-GS in in those patients that have tumors characterized by being ER + , HER2-, having stage pT2N0 or pT1N1 (1 lymph-node) and being of ductal/no special type (NST). The GEP-indication further depends on tumor size and also on grade [11].

Histologic grade clearly plays an important role in tailoring aCT, both directly and indirectly. Considering our earlier data on the existence of substantial variation in grading in daily pathology practice, we decided to evaluate the role of grading in tailoring adjuvant systemic therapy in a nationwide setting, taking both the past and current Dutch IBC-guideline into consideration.

\section{Material and methods}

\section{Key objectives}

The key-objectives of this study were to evaluate the importance of grading in tailoring adjuvant systemic therapy within the past and current Dutch breast cancer guideline, by identifying specific groups of patients for whom the systemic therapy indication depends on histologic grade. Second, we evaluated guideline adherence to the past Dutch breast cancer guideline, and we evaluated which factors, among which histologic grade, may have influenced this.

\section{Study population}

Data were primarily extracted from the nationwide Dutch Pathology Registry (PALGA). All synoptic pathology reports of IBC resection-specimens in the Netherlands, obtained between January 1, 2013, and December 1, 2016, were extracted from PALGA, including $n=48,667$ reports from 42,705 patients. From each report we extracted patient- (sex, age, neoadjuvant treatment) and tumor characteristics (size, grade, histologic subtype, and ER-, PR- and HER2-status).

Reports of patients without a primary tumor $(n=2104)$ were excluded. Furthermore, reports from patients who received neoadjuvant treatment $(n=5829)$ were excluded, because treatment for these patients is based upon biopsies, whereas biomarkers like grade, and receptor-status may alter after systemic treatment [16-21], and as such may differ from the initial biopsy. For synchronous IBC, defined as ipsilateral IBC within six months after the first IBC resection-specimen report, only the first report was included, as this tumor is usually the index-tumor on which treatment decisions are based. Remaining patients with $>1$ pathology report $(n=1495)$, which concerned bilateral tumors in the majority (>90\%), were excluded, as it could not be determined which tumor was considered the index-tumor. Lastly, we excluded reports with any missing data (which concerned missing values on grade, ER/PR-, and HER2-receptor status) (eFigure 1).

To evaluate the role of grading in tailoring adjuvant systemic therapy in daily practice, the pathology-specific data were linked to treatment data from the Netherlands Cancer Registry (NCR) adding information on adjuvant systemic treatment and information on $\mathrm{N}$-status. In the final step of linking, $<5 \%$ of patients (1454) could not be matched, leaving a total of 30,843 IBC patients for data analysis (eFigure 1).

This study was approved by the scientific and privacy committee of PALGA and the monitory board of the NCR.

\section{Histologic grade and other determinants}

Grade was assessed according to the modified Bloom and Richardson guideline, which combines three sub-scores (nuclear pleomorphism, tubule formation and mitotic count), resulting in a total score and derived grade [22, 23]. The combined ER/PR receptor-status was considered positive when $\geq 10 \%$ of tumor cells showed nuclear staining by immunohistochemistry (IHC) for either or both ER and PR, which is the cutoff used in the Netherlands [12]. Based on guideline cutoffs, tumor size was categorized 
( $\leq 1 \mathrm{~cm}, 1.1-2 \mathrm{~cm},>2 \mathrm{~cm})$. For age, we used different cutoffs based on the guideline indication, as this was deemed clinically most relevant. For GEPs, we only presented numbers on 70-GS, as 21-GS was barely used in the Netherlands between 2013 and $2016(<1 \%)$ [24].

\section{Adjuvant systemic therapy and grading within the past and present guideline}

According to the guideline that was valid during the study period (2013-2016) [25], four patient groups had an aCTindication. First this included all $\mathrm{N}+$ patients $<70$ years (subgroup 1). Second this concerned N0 patients $<70$ years with unfavorable characteristics, which were defined as age $<35$ years (except grade I tumors $\leq 1 \mathrm{~cm}$ ) (subgroup 2 ), or, within patients aged 35-70, grade II-III tumors of 1.1-2 cm (subgroup 3), and all tumors $>2 \mathrm{~cm}$ (subgroup 4).

When specifically focusing on grade, it can be concluded that the aCT-indication according to the 2013-2016 guideline specifically depended on grade (i.e. grade was the determinative factor) in patients $<35$ years with a N0 tumor $\leq 1 \mathrm{~cm}$, and in patients aged 35-70 with a N0 tumor between 1.1 and $2 \mathrm{~cm}$, as aCT was indicated when their tumor was graded as $\geq$ grade II.

To evaluate whether accurate grading by pathologists remains relevant, we then evaluated grading within the current Dutch breast cancer guideline, which was published in 2019 [11]. Currently, aCT is indicated in $\mathrm{N}+$ patients $<70$ years (except grade I tumors $<2 \mathrm{~cm}$ ) (subgroup 1), and patients $<70$ years $\mathrm{N} 0 / \mathrm{NO}(\mathrm{i}+) / \mathrm{N} 1(\mathrm{mi})$ with unfavorable characteristics. These unfavorable characteristics are defined as age $<35$ years with a grade I tumor $>2 \mathrm{~cm}$, or a grade II/III tumor $>1 \mathrm{~cm}$ (subgroup 2), age 35-70 with a grade I tumor $>3 \mathrm{~cm}$, a grade II tumor $>2 \mathrm{~cm}$, or a grade III tumor $>1 \mathrm{~cm}$ (subgroup 3). Lastly, aCT is indicated in all HER2-overexpressing tumors (subgroup 4).

Thus the aCT indication within the current guideline depends on grade in three specific patient subgroups. First this concerns patients $<35$ years, N0/N0(i+)/N1(mi) with a HER2-negative tumor between 1.1 and $2 \mathrm{~cm}$. Second, this concerns patients aged 35-70, N1-3, and a hormonepositive, HER2-negative tumor $\leq 2 \mathrm{~cm}$. Lastly, this concerns patients aged $35-70, \mathrm{~N} 0 / \mathrm{NO}(\mathrm{i}+) / \mathrm{N} 1(\mathrm{mi})$ with a hormone receptor positive, HER2-negative tumor between 1.1 and $3 \mathrm{~cm} \mathrm{[11].}$

In addition, within the current guideline, grading also plays a role in tailoring (aET). Overall, aET is indicated in patients of all ages with an ER- and/or PR-positive tumor receptor status and N1-status (including (N1(mi)), while in case of an N0-status (including $\mathrm{NO}(\mathrm{i}+)$ ), aET is only indicated in grade I tumors $>2 \mathrm{~cm}$, and $\geq$ grade II tumors $>1 \mathrm{~cm}$. Thus, for N0/N0 $(\mathrm{i}+)$ patients with a hormone-positive tumor between 1.1 and $2 \mathrm{~cm}$, the aET-indication is determined by grade.

\section{Statistical analysis}

Patient-, tumor- and treatment characteristics were summarized using counts and proportions, and means and standard deviations.

First, we identified patients for whom the aCT-indication, when strictly applying the 2013-2016 guideline, depended on grade. We then performed the same analyses for the 2019 guideline, and we also identified patients for whom the aETindication would depend on grade, as this was added in the 2019 guideline. Second, we calculated which proportion of patients with an aCT-indication according to the 2013-2016 guideline actually received aCT. Third, the relation of grade and other clinicopathologic variables (age, ER/PRand HER2-receptor status, tumor size) and 70-GS use with aCT-administration was evaluated by multivariate logistic regression for the overall population with a 2013-2016 guideline aCT-indication (i.e. all four subgroups). Adjusted odds ratios (AORs) and 95\% confidence intervals (CIs) were provided for aCT versus no aCT. Grade I was taken into account as reference category for grade. Lastly, to identify factors that may have influenced guideline adherence with regard to $\mathrm{aCT}$, within the four subgroups with a guideline aCT-indication, we compared clinicopathologic variables (grade, ER/PR- and HER2-receptor status, age, tumor size) and 70-GS-use between patients who did and did not receive $\mathrm{aCT}$, using counts and proportions, which were tested by means of a $\chi^{2}$-test. For age, a cutoff of $\geq 60$ years was used, as a considerable group of patients with an aCT indication was aged between 60 and 70 years, which may have influenced guideline adherence.

$p$-values $<0.05$ were considered statistically significant. All statistical analyses were performed by using IBM SPSS Statistics version 15.0.0.2.

\section{Results}

Characteristics of the 30,843 included patients are summarized in Table 1 . The overall mean age was 62.0 years, while about a quarter of patients were $\geq 70$ years. Only 245 males were included $(0.8 \%)$. Patients were N0 in roughly two thirds of cases $(68.6 \%)$ and a similar percentage of patients underwent breast conserving surgery $(66.1 \%)$. Mean tumor size was just under $2 \mathrm{~cm}$ and the majority of tumors (84.7\%) were of ductal/no special type (NST) subtype. Hormone-receptor positivity was reported in $87.6 \%$ of tumors and $10.0 \%$ were HER2-receptor positive.

Overall, aCT was administered in nearly one third of patients $(32.3 \%)$, more than half of all patients received 
Table 1 Characteristics of a Dutch nationwide cohort of breast cancer patients $(n=30,843)$, without neo-adjuvant treatment, with a single synoptic resection- specimen pathology report between 2013 and 2016

\begin{tabular}{|c|c|}
\hline Characteristics & Total $(N=30,843)$ \\
\hline Age (years) [mean (SD)] & $62.0(12.0)$ \\
\hline$<60$ years & $12,572(40.8 \%)$ \\
\hline$\geq 60$ years & $18,271(59.2 \%)$ \\
\hline$<70$ years & $22,338(72.4 \%)$ \\
\hline$\geq 70$ years & $8505(27.6 \%)$ \\
\hline \multicolumn{2}{|l|}{$\operatorname{Sex}[n(\%)]$} \\
\hline Female & $30,598(99.2 \%)$ \\
\hline Male & $245(0.8 \%)$ \\
\hline \multicolumn{2}{|l|}{ Lymph-node status $[n(\%)]$} \\
\hline N0 & $21,148(68.6 \%)$ \\
\hline N1 & $7295(23.7 \%)$ \\
\hline $\mathrm{N} 2$ & $996(3.2 \%)$ \\
\hline N3 & $606(2.0 \%)$ \\
\hline $\mathrm{N}$ unknown & $798(2.6 \%)$ \\
\hline \multicolumn{2}{|l|}{ Type of surgery $[n(\%)]$} \\
\hline Mastectomy & $10,463(33.9 \%)$ \\
\hline Breast conserving & $20,380(66.1 \%)$ \\
\hline Tumor size $(\mathrm{cm})$ [mean (SD)] & $1.9(1.3)$ \\
\hline \multicolumn{2}{|l|}{ T-stage } \\
\hline $\mathrm{T} 1$ & $21,393(69.4 \%)$ \\
\hline $\mathrm{T} 2$ & $8383(27.2 \%)$ \\
\hline $\mathrm{T} 3$ & $819(2.7 \%)$ \\
\hline $\mathrm{T} 4$ & $248(0.8 \%)$ \\
\hline \multicolumn{2}{|l|}{ Histologic subtype $[n(\%)]$} \\
\hline Ductal & $26,121(84.7 \%)$ \\
\hline Lobular & $3982(12.9 \%)$ \\
\hline Other & $740(2.4 \%)$ \\
\hline \multicolumn{2}{|l|}{ Histologic grade $[n(\%)]$} \\
\hline Grade I & $8633(28.0 \%)$ \\
\hline Grade II & $14,682(47.6 \%)$ \\
\hline Grade III & $7528(24.4 \%)$ \\
\hline \multicolumn{2}{|l|}{ ER/PR receptor status $[n(\%)]$} \\
\hline Positive & $27,008(87.6 \%)$ \\
\hline Negative & $3835(12.4 \%)$ \\
\hline \multicolumn{2}{|l|}{ HER2-receptor status $[n(\%)]$} \\
\hline Positive & $3070(10.0 \%)$ \\
\hline Negative & $27,773(90.0 \%)$ \\
\hline Triple negative status $[n(\%)]$ & $2884(9.4 \%)$ \\
\hline Chemotherapy $[n(\%)]$ & $9950(32.3 \%)$ \\
\hline Endocrine therapy $[n(\%)]$ & $17,041(55.3 \%)$ \\
\hline Radiotherapy $[n(\%)]$ & $22,186(71.9 \%)$ \\
\hline Targeted therapy $[n(\%)]$ & $2281(7.4 \%)$ \\
\hline $70-\mathrm{GS}[n(\%)]$ & $3291(10.7 \%)$ \\
\hline
\end{tabular}

aET $(55.3 \%)$, and $71.9 \%$ underwent radiotherapy. Targeted therapy was administered in $7.4 \%$ of patients, and consisted of the anti-HER 2 agent Trastuzumab in nearly all cases.
Little over ten percent of patients had a GEP performed, which concerned 70-GS in virtually all cases. The majority of patients with a 70-GS performed were assigned to the 70-GS low-risk category $(n=2026,61.6 \%)$.

\section{Grading}

We identified $7744(25.1 \%)$ patients for whom grade would be the determinative factor for their aCT-indication, when strictly applying the guideline that was valid during the study period (2013-2016) (eTable 1). When applying the guideline that was published in 2019 [11], we identified an increase in the percentage of patients for whom the aCTindication would depend on grade, being $35.2 \%(n=10,869)$ (eTable 2). In addition, new in the current guideline, the indication for aET would depend on grade in 9,173 (29.7\%) patients (eTable 3).

Applying the Dutch breast cancer guideline that was valid between 2013 and 2016, we identified 14,954 patients (48.5\%) with an aCT-indication (Table 2). Of this group, only 9,010 patients $(60.3 \%)$ actually received aCT. As 9,950 patients actually received aCT, 940 patients $(9.4 \%)$ apparently did so without having a guideline-indication. Administration of aCT decreased slightly between 2013 and 2015, while a considerable decrease of $12.8 \%$ was observed in 2016 (Fig. 1).

In general, for all patients with an aCT-indication, aCTadministration was significantly more apparent in patients with tumors of higher grade [adjusted OR (AOR) grade II: 1.4 (95\%CI 1.3-1.7), AOR grade III: 4.7 (95\%CI 4.1-5.4)], HER2-receptor-positive tumors [AOR 4.9 (95\%CI 4.1-5.8)], and tumors of larger size [AOR per $\mathrm{cm}$ increase: $1.4(95 \% \mathrm{CI}$ 1.3-1.4)]. In contrast, patients with hormone-receptor-positive tumors (AOR: 0.4 (95\% CI 0.4-0.5), an age $\geq 60$ years (AOR: 0.3 (95\% CI 0.3-0.3), or patients with a 70-GS performed (irrespective of 70-GS result-category) (AOR: 0.4 (95\%CI 0.4-0.4) had significantly lower odds of receiving aCT (Table 3).

Guideline adherence was most apparent for patients $<35$ years with an aCT-indication $(89.1 \%)$, while it was lowest for the group of N0-patients aged 35-69 with tumors of $1.1-2 \mathrm{~cm}$ size (45.4\%) (Table 4). Notably, within the latter group, only $20.9 \%$ of patients with grade II tumors received aCT, whereas $78.8 \%$ of patients with grade III tumors received aCT $(p=0.000)$. In addition, 70-GS-use was highest within this group $(30.2 \%)$ and aCT was only administered in $34.6 \%$ of these patients.

As to the role of the 70-GS, this was used in 2,950 patients with a guideline-aCT-indication (19.7\%), and only about a third of these patients received aCT (Table 4). We also observed an only marginal increase in the use of 70-GS in the years between 2013 and 2015, followed by a considerable increase of $12.4 \%$ in 2016 (Fig. 1). 
Table 2 Number of breast cancer patients from our dataset (2013-2016) with an indication for adjuvant chemotherapy $(\mathrm{aCT})$ according to the Dutch breast cancer guideline between 2013 and 2016 vs. number of breast cancer patients who actually received aCT

\begin{tabular}{lll}
\hline Characteristics & $\begin{array}{l}\text { Number of patients with an } \\
\text { indication for aCT }\end{array}$ & $\begin{array}{l}\text { Number of patients } \\
\text { who received aCT }\end{array}$ \\
\hline $\begin{array}{l}\text { All patients }<70 \text { years and N+ } \\
\text { Patients up to } 70 \text { years and N0 }\end{array}$ & 6378 & 4562 \\
$\quad \begin{array}{l}\text { Age }<35 \text { years: grade I tumors }>1 \mathrm{~cm} \text {, grade II-III all } \\
\quad \text { tumor sizes }\end{array}$ & 202 & 180 \\
Age $\geq 35$ years: tumor $1.1-2 \mathrm{~cm}$, grade II-III tumor & 5459 & 2476 \\
Age $\geq 35:$ tumor $>2 \mathrm{~cm}$ & 2915 & 1792 \\
All other patients & - & 940 \\
Total number of patients $(n=30.843)$ & $14,954(48.5 \%)$ & $9950(32.3 \%)$ \\
\hline
\end{tabular}

Fig. 1 Patients with a strict aCT guideline indication according to the 2013-2016 guideline
Table 3 Indicators of guideline adherence (aCT-administration) in 14,954 IBC patients with a guideline indication for adjuvant chemotherapy (aCT) according to the Dutch guideline

(2013-2016)

\section{Patients with a guideline aCT indication}

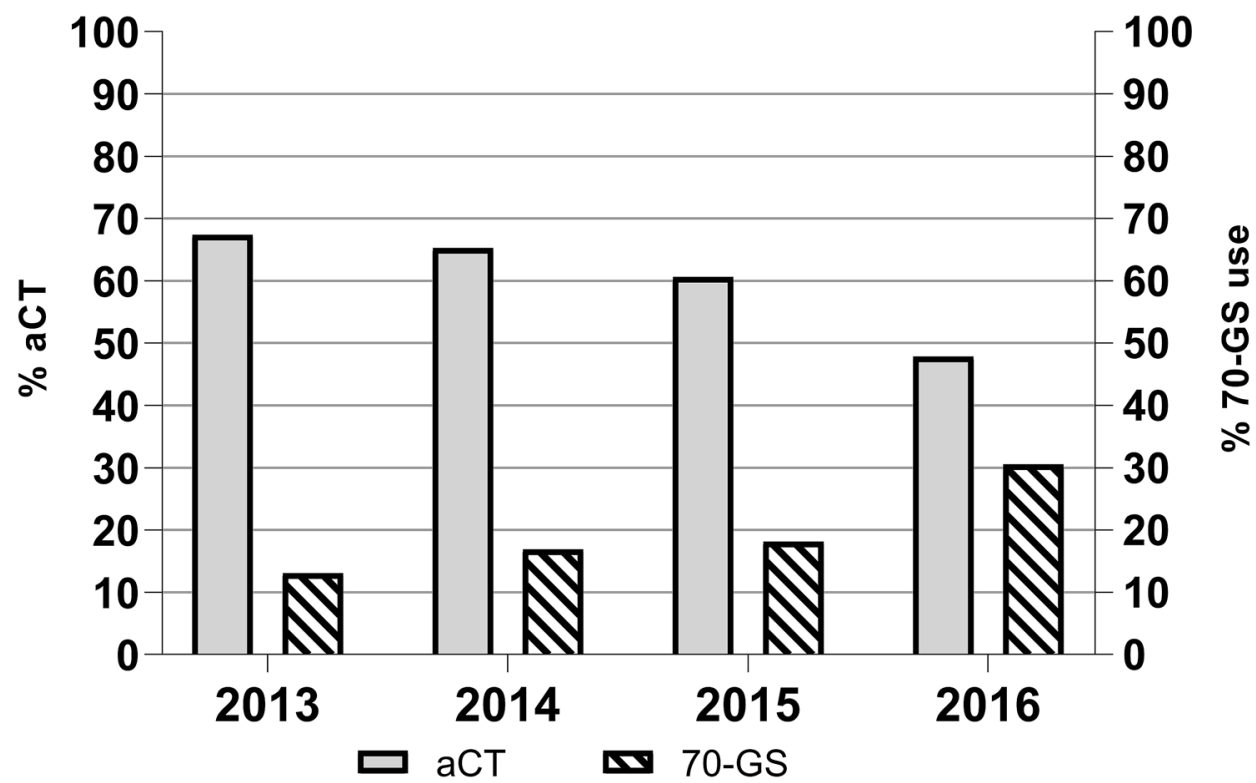

Patient- and tumor characteristics

Number of patients

Adjusted OR (95\% CI)*

Histologic grade

Grade I

Grade II

Grade III

ER/PR positive receptor status

HER2 positive receptor status

Age $\geq 60$ years

Tumor size $(\mathrm{cm})$

$1732(11.6 \%)$
$8333(55.7 \%)$
$4889(32.7 \%)$
$12,704(85.0 \%)$
$1921(12.8 \%)$
$6084(40.7 \%)$
$2.1(1.3) * *$
$2950(19.7 \%)$

1

$1.5(1.3-1.7)$

$4.7(4.1-5.4)$

$0.4(0.4-0.5)$

$4.9(4.1-5.8)$

$0.3(0.3-0.3)$

$1.4(1.3-1.4)$

$0.4(0.4-0.4)$

*Calculated by multivariate logistic regression; adjusted for ER/PR-receptor status, HER2-receptor status, histologic grade, age, tumor size and 70-GS use

**Mean (SD) 
Table 4 Characteristics of IBC patients with an indication for adjuvant chemotherapy (aCT) according to the Dutch guideline (2013-2016) who received aCT versus patients with an aCT indication who did not receive aCT

\begin{tabular}{|c|c|c|c|c|}
\hline Characteristics & Total & aCT received & No aCT received & $p$-value* \\
\hline Patients $<70$ years, $N+$ tumor & 6378 & $4562(71.5 \%)$ & $1816(28.5 \%)$ & 0.000 \\
\hline \multicolumn{5}{|l|}{ Histologic grade } \\
\hline Grade I & 1316 & $628(477 \%)$ & $688(52.3 \%)$ & \multirow[t]{3}{*}{0.000} \\
\hline Grade II & 3245 & $2363(72.8 \%)$ & $882(27.2 \%)$ & \\
\hline Grade III & 1817 & $1571(86.5 \%)$ & $246(13.5 \%)$ & \\
\hline \multicolumn{5}{|l|}{ Receptor status } \\
\hline ER and/or PR positive & 5657 & $3899(68.9 \%)$ & $1758(31.1 \%)$ & 0.000 \\
\hline HER2 positive & 858 & $794(92.5 \%)$ & $64(7.5 \%)$ & 0.000 \\
\hline Age $\geq 60$ years & 2403 & $1394(58.0 \%)$ & $1009(42.0 \%)$ & 0.000 \\
\hline \multicolumn{5}{|l|}{ Tumor size } \\
\hline Tumor size $\leq 1.0 \mathrm{~cm}$ & 623 & $321(51.5 \%)$ & $302(48.5 \%)$ & \multirow[t]{3}{*}{0.000} \\
\hline Tumor size $1.1-2 \mathrm{~cm}$ & 2826 & $1869(66.1 \%)$ & $957(33.9 \%)$ & \\
\hline Tumor size $>2 \mathrm{~cm}$ & 2929 & $2372(81.0 \%)$ & $557(19.0 \%)$ & \\
\hline 70-GS & 721 & $240(33.3 \%)$ & $481(66.7 \%)$ & 0.000 \\
\hline Patients $<35$ years, N0 tumor: grade $\mathrm{I}>1 \mathrm{~cm}$, grade II-III & 202 & $180(89.1 \%)$ & $22(10.9 \%)$ & 0.000 \\
\hline \multicolumn{5}{|l|}{ Histologic grade } \\
\hline Grade I & 12 & $9(75.0 \%)$ & $3(25.0 \%)$ & \multirow[t]{3}{*}{0.000} \\
\hline Grade II & 61 & $46(75.4 \%)$ & $15(24.6 \%)$ & \\
\hline Grade III & 129 & $125(96.9 \%)$ & $4(3.1 \%)$ & \\
\hline \multicolumn{5}{|l|}{ Receptor status } \\
\hline ER and/or PR positive & 112 & $93(83.0 \%)$ & $19(17.0 \%)$ & 0.002 \\
\hline HER2 positive & 43 & $40(93.0 \%)$ & $3(7.0 \%)$ & 0.353 \\
\hline \multicolumn{5}{|l|}{ Tumor size } \\
\hline Tumor size $\leq 1.0 \mathrm{~cm}$ & 37 & $26(70.3 \%)$ & $11(29.7 \%)$ & \multirow[t]{3}{*}{0.000} \\
\hline Tumor size $1.1-2 \mathrm{~cm}$ & 99 & $91(91.9 \%)$ & $8(8.1 \%)$ & \\
\hline Tumor size $>2 \mathrm{~cm}$ & 66 & $63(95.5 \%)$ & $3(4.5 \%)$ & \\
\hline 70-GS & 11 & $3(27.3 \%)$ & $8(72.7 \%)$ & 0.073 \\
\hline Patients $35-69$ years, N0 tumor: $1.1-2 \mathrm{~cm}$, grade II-III & 5459 & $2476(45.4 \%)$ & $2,983(54.6 \%)$ & 0.000 \\
\hline \multicolumn{5}{|l|}{ Histologic grade } \\
\hline Grade II & 3686 & $1078(29.2 \%)$ & $2608(70.8 \%)$ & \multirow[t]{2}{*}{0.000} \\
\hline Grade III & 1773 & $1398(78.8 \%)$ & $375(21.2 \%)$ & \\
\hline \multicolumn{5}{|l|}{ Receptor status } \\
\hline ER and/or PR positive & 4636 & $1782(38.4 \%)$ & $2854(61.6 \%)$ & 0.000 \\
\hline HER2 positive & 690 & $622(90.1 \%)$ & $68(9.9 \%)$ & $\mathbf{0 . 0 0 0}$ \\
\hline Age $\geq 60$ years & 2442 & $774(31.7 \%)$ & $1668(68.3 \%)$ & 0.000 \\
\hline 70-GS & 1648 & $571(34.6 \%)$ & $1077(65.4 \%)$ & 0.000 \\
\hline Patients $35-69$ years, N0 tumor: $>2 \mathrm{~cm}$ & 2915 & $1792(61.5 \%)$ & $1123(38.5 \%)$ & 0.000 \\
\hline \multicolumn{5}{|l|}{ Histologic grade } \\
\hline Grade I & 404 & $83(20.5 \%)$ & $321(79.5 \%)$ & \multirow[t]{3}{*}{0.000} \\
\hline Grade II & 1341 & $723(53.9 \%)$ & $618(46.1 \%)$ & \\
\hline Grade III & 1170 & $986(84.3 \%)$ & $184(15.7 \%)$ & \\
\hline \multicolumn{5}{|l|}{ Receptor status } \\
\hline ER and/or PR positive & 2299 & $1248(56.0 \%)$ & $1051(47.2 \%)$ & 0.000 \\
\hline HER2 positive & 330 & $294(89.1 \%)$ & $36(10.9 \%)$ & 0.000 \\
\hline Age $\geq 60$ years & 1239 & $578(46.7 \%)$ & $661(53.3 \%)$ & 0.000 \\
\hline 70-GS & 570 & $204(35.8 \%)$ & $366(64.2 \%)$ & 0.000 \\
\hline
\end{tabular}

*Calculated by means of a $\chi^{2}$ test, bold numbers indicate statistical significance 


\section{Discussion}

Using real-world nationwide data in 30,843 IBC patients, the role of grading in daily practice, in light of both the past and present Dutch breast cancer guidelines, was evaluated.

These data illustrate that grade remains a key-player in tailoring adjuvant systemic therapy, and that the importance of accurate grading has only increased for aCT, as well as $\mathrm{aET}$. As to the role of grading within the guideline that was valid during the study years, our data illustrate that grade played a significant role in tailoring aCT. Whereas the aCTindication theoretically depended on grade in a quarter of IBC patients, grade also played an important role in tailoring aCT de-escalation, as patients with lower grade tumors received aCT significantly less often.

In general, these data illustrate a trend of aCT de-escalation in IBC patients whose risk of distant metastases was deemed low enough to withhold adjuvant systemic treatment. Important supportive clinicopathologic biomarkers tailoring aCT were patients' age, $\mathrm{N}$ status, hormone- and HER2-receptor status, tumor size and grade. A particularly useful tool in aCT de-escalation in the Netherlands has been the 70-GS, whose use increased considerably in 2016, most likely after publication of the MINDACT-trial [26]. In patients with a strict guideline aCT-indication, this increase in 70-GS-use was accompanied by a decrease of aCTadministration. Overall, only a third of patients who had a 70-GS performed, received aCT. It is however important to emphasize that the observed aCT de-escalation can only partially be contributed to 70-GS-use, since, overall, 5944 patients with a strict guideline aCT-indication $(40.7 \%)$ did not receive aCT. Of these patients, only 1932 (32.5\%) had a 70-GS test, leaving $4012(67.5 \%)$ patients, whose guideline non-adherence was probably based on clinicopathologic biomarkers. In addition, guideline (non)adherence may have also been influenced by other patient factors like comorbidity or patient preference. Although we did not have these data, patients of older age were less likely to receive aCT, which may have been related to existing comorbidities.

Considering the 2019 guideline [11], one could conclude that aCT de-escalation, which was already increasingly implemented in daily practice throughout 2013-2016 despite the guideline ("guideline update anticipation"), has now been translated into official guidelines. Next to age and receptor-status, aCT-indication is primarily based on grade, tumor size, and the degree of lymph-node involvement [11]. In addition, there remains a role for the 70-GS as a supportive tool, however, it is important to realize that also the 70-GS-indication itself is guided by grade, histologic subtype, tumor size, $\mathrm{N}$-status and receptor-status [11].
Bearing the clinical implications of grading in mind, it is clear that accurate grading by pathologists is of utmost importance to provide high-quality care. In that respect, we have previously shown that there is substantial variation in grading between Dutch pathology laboratories [15]. For example, $>50 \%$ of Dutch pathology laboratories showed significantly deviant ORs in a multivariate logistic regression model, in which the average laboratory was considered the reference [15]. However, from these data, we cannot conclude which laboratories may grade inaccurately. Nonetheless, considering the fact that grade is the determinative factor in $>10,000$ patients, while $>50 \%$ of Dutch laboratories graded significantly different from the nationwide average, it may be clear that for many thousands of IBC-patients, treatment may have been based on inaccurate grading.

This underlines that maximum effort to minimize differences in grading is urgently required. Therefore, we launched two encouraging initiatives, i.e. laboratoryspecific feedback reports and training of pathologists by e-learning [27, 28]. This is an ongoing process, yet, even after training and feedback, grading variation remains considerable. Therefore, additional avenues should be explored, such as the potential supportive role of artificial intelligence in analyzing histopathology data [29, 30]. In addition, Ki67 is a prognostic proliferation marker that may be of added value, but there is controversy with regard to its clinical utility in routine management due to variation in analytical practice, lack of a standardized procedure for Ki67-assessment, and absence of consensus on cutoff-values [31, 32].

Although this study applies to the Dutch situation, we would like to emphasize that breast cancer guidelines in the Netherlands are generally in accordance with international guidelines $[5-7,9,10,12,33,34]$, which all take grade into account (eTable 4). While for some guidelines primary focus has shifted to GEP-use as a first determinant in deciding whether aCT should be administered [7, 10,33], these guidelines also state that, when GEPs are not available, classic clinicopathologic biomarkers, including grade should be considered. In this light, it is highly relevant to underline that GEPs are not accessible (i.e. $\$ 4.000$ per $21-$ GS, $\$ 3.900$ per 70-GS) nor applicable for every IBC patient [35-42]. For example, probably only up to half of the eligible women in the US receive GEP-testing [40, 41]. Hence, for the majority of patients, both in developing and developed countries, classic pathology biomarkers remain the most important indicator(s) for the need of adjuvant systemic treatment. Moreover, recent evidence shows that, in specific subgroups, the 21-GS score may be accurately predicted based on grade and PR-receptor status, perhaps saving the need for expensive tests [43-47]. 
The short follow-up time precluded outcome analyses. Thus, whether aCT de-escalation in almost $40 \%$ of IBC patients with a strict guideline aCT-indication did not compromise their outcome remains to be elucidated. This important analysis will be performed after longer follow-up.

A limitation of this study is the exclusion of patients who received neoadjuvant treatment. As neoadjuvant systemic therapy is the preferred initial approach in HER2-driven and TNBC [7], these groups are most likely underrepresented in our study. Hence, we would like to emphasize that the 30,843 IBC patients within our study do not represent the overall population of IBC patients in the Netherlands. However, they do represent the nationwide population of IBC patients who were potentially eligible for adjuvant systemic therapy between 2013 and 2016 .

\section{Conclusions}

This study with nationwide data on 30,843 Dutch primary breast cancer patients illustrates the increasing importance of histologic grading with regard to tailoring adjuvant systemic therapy, as the indications for aCT and aET depend on grade in roughly a third of IBC patients. This is due to the large proportion of patients who fall into the category in which histologic grade finally determines the need for adjuvant therapy when national guidelines are followed. This stresses the need for optimizing grading by pathologists, to diminish the risk of worse patient outcome due to non-optimal treatment decisions.

Supplementary Information The online version contains supplementary material available at https://doi.org/10.1007/s10549-021-06098-7.

Acknowledgements The authors thank the registration team of the Netherlands Comprehensive Cancer Organization (IKNL) for the collection of data for the NCR as well as IKNL staff for scientific advice.

Author contributions Authors CvD, IB, SS and EdW were involved in the design of the study. Data were collected and analysed by CvD. Data interpretation was performed by all authors. CvD wrote the manuscript, which was read and revised by all authors. Funding was obtained by PvD.

Funding This study was supported by the Quality Foundation of the Dutch Association of Medical Specialists (SKMS). Funding was obtained by PD. Role of the funding source The funding source had no role in the design and conduct of this study, nor did it have a role in the review or approval of the manuscript and the decision to submit the manuscript for publication.

Data availability Data are available upon request from PALGA (the nationwide registry of histo- and cytopathology in the Netherlands) and the Netherlands Cancer Registry (NCR).

\section{Compliance with ethical standards}

Conflict of interest The authors have declared no conflicts of interest.
Research involving human participants and/or animals This study was assessed and approved by the scientific and privacy committee of PALGA (the nationwide network and registry of histo- and cytopathology in the Netherlands) and the monitory board of the Netherlands Cancer Registry (NCR). As this study was performed retrospectively on anonymised data, and did not involve subjecting patients to anything, consent from the ethics committee was not required according to the Dutch law. We only ever received fully anonymised data. Data of patients who object against the scientific use of their (anonymised) data are not included in the PALGA database. Therefore waiver of informed consent is applicable. All data were retrieved and handled in compliance with the General Data Protection Regulation (GDPR).

Open Access This article is licensed under a Creative Commons Attribution 4.0 International License, which permits use, sharing, adaptation, distribution and reproduction in any medium or format, as long as you give appropriate credit to the original author(s) and the source, provide a link to the Creative Commons licence, and indicate if changes were made. The images or other third party material in this article are included in the article's Creative Commons licence, unless indicated otherwise in a credit line to the material. If material is not included in the article's Creative Commons licence and your intended use is not permitted by statutory regulation or exceeds the permitted use, you will need to obtain permission directly from the copyright holder. To view a copy of this licence, visit http://creativecommons.org/licenses/by/4.0/.

\section{References}

1. World Health Organization (WHO) (2019) Breast cancer; early diagnosis and screening. https://www.who.int/cancer/prevention /diagnosis-screening/breast-cancer/en/. Accessed 14 Feb 2020

2. Netherlands Cancer Registry supplied by IKNL (2020). https:// www.cijfersoverkanker.nl. Accessed 14 Feb 2020

3. National Institute for Health and Environment (RIVM), Ministry of Health, Welness and Sport (2019). Chance of breast cancer https://www.rivm.nl/bevolkingsonderzoek-borstkanker/wat-isborstkanker/kans-op-borstkanker. Accessed 10 Oct 2019

4. Waks AG, Winer EP (2019) Breast cancer treatment: a review. JAMA 321(3):288-300

5. Henry NL, Somerfield MR, Abramson VG et al (2016) Role of patient and disease factors in adjuvant systemic therapy decision making for early-stage, operable breast cancer: American Society of Clinical Oncology Endorsement of Cancer Care Ontario Guideline Recommendations. J Clin Oncol 34(19):2303-2311

6. Henry NL, Somerfield MR, Abramson VG et al (2019) Role of patient and disease factors in adjuvant systemic therapy decision making for early-stage, operable breast cancer: update of the ASCO endorsement of the Cancer Care Ontario Guideline. J Clin Oncol 37(22):1965-1977

7. Burstein HJ, Curigliano G, Loibl S et al (2019) Estimating the benefits of therapy for early stage breast cancer the St Gallen International Consensus Guidelines for the Primary Therapy of Early Breast Cancer 2019. Ann Oncol 30(10):1541-1557. https ://doi.org/10.1093/annonc/mdz235

8. Curigliano G, Burstein HJ, Winer EP et al. (2017) De-escalating and escalating treatments for early-stage breast cancer: the St. Gallen International Expert Consensus Conference on the Primary Therapy of Early Breast Cancer 2017. Ann Oncol 28(8):1700-1712

9. Andre F, Ismaila N, Henry NL et al (2019) Use of biomarkers to guide decisions on adjuvant systemic therapy for women with early-stage invasive breast cancer: ASCO clinical practice 
guideline update-integration of results from TAILORx. J Clin Oncol 37(22):1956-1964

10. Goetz MP, Gradishar WJ, Anderson BO et al (2019) NCCN guidelines insights: breast cancer, version 3.2018. J Natl Compr Cancer Netw 17(2): 118

11. The Netherlands Comprehensive Cancer Organization (IKNL) (2019). Oncoline: cancer clinical practice guidelines (the Netherlands). https://www.oncoline.nl/. Accessed 8 May 2020

12. Eisen A, Fletcher GG, Gandhi S et al (2015) Optimal systemic therapy for early breast cancer in women: a clinical practice guideline. Curr Oncol 22(Suppl 1):S67-81

13. Rakha EA, El-Sayed ME, Lee AH et al (2008) Prognostic significance of Nottingham histologic grade in invasive breast carcinoma. J Clin Oncol 26(19):3153-3158

14. Rakha EA, Reis-Filho JS, Baehner F et al (2010) Breast cancer prognostic classification in the molecular era: the role of histological grade. Breast Cancer Res 12(4):207

15. van Dooijeweert C, van Diest PJ, Willems SM et al (2020) Significant inter- and intra-laboratory variation in grading of invasive breast cancer: a nationwide study of 33,043 patients in the Netherlands. Int J Cancer 14(3):769-780

16. Adams AL, Eltoum I, Krontiras H, Wang W, Chhieng DC (2008) The effect of neoadjuvant chemotherapy on histologic grade, hormone receptor status, and HER2/neu status in breast carcinoma. Breast J 14(2):141-146

17. Yin HF, Wang YH, Qin XQ et al (2009) Effect of neoadjuvant chemotherapy on histologic grade and expression of biological markers in breast cancer. Zhonghua zhong liu za zhi [Chin J Oncol] 31(11):858-862

18. Zheng S, Zhang BL, Xiao T et al (2011) Comparison of histopathologic changes and expression of biomarkers in breast carcinoma before and after neoadjuvant chemotherapy. Zhonghua bing li xue za zhi Chin J Pathol 40(7):465-470

19. Xian Z, Quinones AK, Tozbikian G, Zynger DL (2017) Breast cancer biomarkers before and after neoadjuvant chemotherapy: does repeat testing impact therapeutic management? Hum Pathol 62:215-221

20. Yang L, Zhong X, Pu T, Qiu Y, Ye F, Bu H (2018) Clinical significance and prognostic value of receptor conversion in hormone receptor positive breast cancers after neoadjuvant chemotherapy. World J Surg Oncol 16(1):51

21. Yang YF, Liao YY, Li LQ, Xie SR, Xie YF, Peng NF (2013) Changes in ER, PR and HER2 receptors status after neoadjuvant chemotherapy in breast cancer. Pathol Res Pract 209(12):797-802

22. Bloom HJ, Richardson WW (1957) Histological grading and prognosis in breast cancer; a study of 1409 cases of which 359 have been followed for 15 years. Br J Cancer 11(3):359-377

23. Elston CW, Ellis IO (1991) Pathological prognostic factors in breast cancer. I. The value of histological grade in breast cancer: experience from a large study with long-term follow-up. Histopathology 19(5):403-410

24. van Steenhoven JEC, Kuijer A, Schreuder K et al (2019) The changing role of gene-expression profiling in the era of de-escalating adjuvant chemotherapy in early-stage breast cancer. Ann Surg Oncol 26(11):3495-3501

25. The Netherlands Comprehensive Cancer Organisation (IKNL) (2017). Oncoline: breast cancer guideline. https://www.oncoline. nl/borstkanker. Accessed 4 Mar 2019

26. Cardoso F, van't Veer LJ, Bogaerts J et al (2016) 70-gene signature as an aid to treatment decisions in early-stage breast cancer. N Eng J Med 375(8):717-729

27. van Dooijeweert C, van Diest PJ, Baas IO, van der Wall E, Deckers IA (2020) Variation in breast cancer grading: the effect of creating awareness through laboratory-specific and pathologistspecific feedback reports in 16734 patients with breast cancer. $\mathrm{J}$ Clin Pathol 73:793
28. van Dooijeweert C, Deckers IAG, de Ruiter EJ et al (2020) The effect of an e-learning module on grading variation of (pre)malignant breast lesions. Mod Pathol. https://doi.org/10.1038/s4137 9-020-0556-6

29. Veta M, van Diest PJ, Jiwa M, Al-Janabi S, Pluim JP (2016) Mitosis counting in breast cancer: object-level interobserver agreement and comparison to an automatic method. PLoS ONE 11(8):e0161286

30. Bejnordi EB, Veta M, Diest PJ et al (2017) Diagnostic assessment of deep learning algorithms for detection of lymph node metastases in women with breast cancer. JAMA 318(22):2199-2210

31. Dowsett M, Nielsen TO, A'Hern R et al (2011) Assessment of Ki67 in breast cancer: recommendations from the International Ki67 in Breast Cancer working group. J Natl Cancer Inst 103(22):1656-1664

32. Penault-Llorca F, Radosevic-Robin N (2017) Ki67 assessment in breast cancer: an update. Pathology 49(2):166-171

33. Cardoso F, Kyriakides S, Ohno S et al (2019) Early breast cancer: ESMO clinical practice guidelines for diagnosis, treatment and follow-up †. Ann Oncol 30(8):1194-1220

34. Duffy MJ, Harbeck N, Nap M et al (2017) Clinical use of biomarkers in breast cancer: updated guidelines from the European Group on Tumor Markers (EGTM). Eur J Cancer 75:284-298

35. Orucevic A, Heidel RE, Bell JL (2016) Utilization and impact of 21-gene recurrence score assay for breast cancer in clinical practice across the United States: lessons learned from the 2010 to 2012 National Cancer Data Base analysis. Breast Cancer Res Treat 157(3):427-435

36. Roberts MC, Kurian AW, Petkov VI (2019) Uptake of the 21-gene assay among women with node-positive, hormone receptor-positive breast cancer. J Natl Compr Canc Netw 17(6):662-668

37. Jasem J, Amini A, Rabinovitch R et al (2016) 21-gene recurrence score assay as a predictor of adjuvant chemotherapy administration for early-stage breast cancer: an analysis of use, therapeutic implications, and disparity profile. J Clin Oncol 34(17):1995-2002

38. Press DJ, Ibraheem A, Dolan ME, Goss KH, Conzen S, Huo D (2018) Racial disparities in omission of oncotype DX but no racial disparities in chemotherapy receipt following completed oncotype DX test results. Breast Cancer Res Treat 168(1):207-220

39. Weldon CB, Trosman JR, Gradishar WJ, Benson AB, Schink JC (2012) Barriers to the use of personalized medicine in breast cancer. J Oncol Pract 8(4):e24-e31

40. Davis BA, Aminawung JA, Abu-Khalaf MM et al (2017) Racial and ethnic disparities in oncotype DX test receipt in a Statewide Population-Based Study. J Natl Compr Canc Netw 15(3):346-354

41. Zhang L, Hsieh MC, Petkov V, Yu Q, Chiu YW, Wu XC (2020) Trend and survival benefit of Oncotype DX use among female hormone receptor-positive breast cancer patients in 17 SEER registries, 2004-2015. Breast Cancer Res Treat 180(2):491-501

42. Ricks-Santi LJ, McDonald JT (2017) Low utility of oncotype $\mathrm{DX}(\mathrm{R})$ in the clinic. Cancer Med 6(3):501-507

43. Wu SG, Zhang WW, Wang J et al (2019) Progesterone receptor status and tumor grade predict the 21-gene recurrence score of invasive lobular breast cancer. Biomark Med 13(12):1005-1012

44. Allison KH, Kandalaft PL, Sitlani CM, Dintzis SM, Gown AM (2012) Routine pathologic parameters can predict Oncotype DXTM recurrence scores in subsets of ER positive patients: who does not always need testing? Breast Cancer Res Treat 131(2):413-424

45. Huang JL, Kizy S, Marmor S et al (2018) Tumor grade and progesterone receptor status predict 21-gene recurrence score in early stage invasive breast carcinoma. Breast Cancer Res Treat 172(3):671-677

46. Yoo SH, Kim T-Y, Kim M et al (2019) Development of a nomogram to predict the recurrence score of 21-gene prediction assay in 
hormone receptor-positive early breast cancer. Clin Breast Cancer 20:98

47. Orucevic A, Bell JL, King M, McNabb AP, Heidel RE (2019) Nomogram update based on TAILORx clinical trial resultsoncotype DX breast cancer recurrence score can be predicted using clinicopathologic data. Breast 46:116-125
Publisher's Note Springer Nature remains neutral with regard to jurisdictional claims in published maps and institutional affiliations. 